\title{
强恒磁场下麦粒㨋虫细胞分裂与细胞内 $\mathrm{P}^{3+}, \mathrm{PO}_{4}^{3-}$ 传递方式之间的关系*
}

\author{
张小云刘 栋** \\ （中国科学技术大学生物系,合肥） \\ 胡 希伟 \\ (中国科学技术大学近代物理系,合肥)
}

\section{关锤词恒定磁场、迥旋半径、局域化、氧进磷酸化}

磁场对细胞生长和分裂的影响, 早有人研究, 但由于各实验者所采用的实验材料和实验条 件不同, 因此结果往往很不一致,有人认为磁场能促进分裂,有的则认为呈抑制效应 ${ }^{[4-4)}$. 我们 以单细胞动物麦粒腥虫 (Blepharisma) 为材料, 以不同强度的恒定磁场和处理时间来研究磁 场对它的效应. 结果表明, $0.05 \mathrm{~T}$ 磁场能促进细胞生长,而 $1.4 \mathrm{~T}$ 磁场则抑制细胞分裂。

我们的研究表明, 弱强磁场对细胞分裂之影响是通过一系列的细胞内变化形成的. 如酸 性磷酸酶的分布和活性在强场下都发生变化,细胞内的微管结构会因为强磁场的处理而解聚, 还有细胞在磁场下因磁通量变化而导致的感应电流会使细胞内物质传递的改变. 其中还应考 虑到在磁场下带电粒子的运动会受到迴旋半径的约束, 为此我们计算了细胞内的 $\mathrm{P}^{3+}$ 和 $\mathrm{PO}^{3-}$ 在磁场下所道循的迴旋半径, 发现计算结果与磁场影响细胞分裂的现象十分吻合, 可用来合理 地解释实验结果。

\section{一、材料与方法}

恒定磁场由永久磁体产生, 强度为 $0.05,0.1,0.4,1.4 \mathrm{~T}$. 由于不同强度的磁体形状结构 不同，因此处理细胞的空间亦不同, $0.4 \mathrm{~T}$ 磁体空间为 $15 \mathrm{~cm} \times 15 \mathrm{~cm}$, 故可放置培养皿直接培 养细胞, 但 $1.4 \mathrm{~T}$ 磁体空间 $\varphi$ 为 $5 \mathrm{~mm}$, 只能放置极细的试管培养细胞, 为此尽管培养温度相同 为 $23 \pm 2{ }^{\circ} \mathrm{C}$, 处理时间也相同, 但各对照组之间细胞生长仍有区别, 故只以同一磁场强度的细胞 生长作对照, 而各对照组之间由于培养容器不同而不作对照. 细胞观察和计数直接在体视显 微镜下进行, 并求出各次实验的平均值.

\section{二、结果和讨论}

实验结果表明, 磁场对细胞的生物效应与磁场强度及处理时间有密切关系, 在 $0.05 \mathrm{~T}$ 的磁 场下, 如只经过一天的处理, 实验组与对照组的细胞数无十分明显的区别, $P>0.05$. 但同样 强度经 $3 \mathrm{~d}$ 或 $5 \mathrm{~d}$ 的处理, 则两组细胞生长明显不同. 在 $0.1 \mathrm{~T}$ 磁场下, 则实验组和对照组的细

本文 1987 年 7 月 20 日收到.

- 国家自然科学基金资助项目。

**现在中国科学院上海植物生理研究所工作. 
胞分裂速度无明显差异。在 $0.4 \mathrm{~T}$ 磁场下, 实验组细胞分裂低于对照组, 细胞分裂受到部分抑 制. 而当磁场强度高达 $1.4 \mathrm{~T}$ 时,则麦粒腥虫的细胞分裂受到了完全的抑制．见表 1.

表 1 麦粒腥虫在不同强度磁场下的分裂情况

\begin{tabular}{|c|c|c|c|c|}
\hline 场强度 (T) & 处理时间 (d) & 起始细胞数 & 最终细胞数 & 对琞组细咆数 \\
\hline 0.05 & $\begin{array}{l}1 \\
3 \\
5\end{array}$ & $\begin{array}{l}10 \\
10 \\
10\end{array}$ & $\begin{array}{r}22 \\
50 \\
149\end{array}$ & $\begin{array}{l}16 \\
30 \\
94\end{array}$ \\
\hline 0.1 & $\begin{array}{l}1 \\
3 \\
5\end{array}$ & $\begin{array}{l}10 \\
10 \\
10\end{array}$ & $\begin{array}{r}25 \\
86 \\
152\end{array}$ & $\begin{array}{r}27 \\
90 \\
157\end{array}$ \\
\hline 0.4 & $\begin{array}{l}1 \\
3 \\
5\end{array}$ & $\begin{array}{l}10 \\
10 \\
10\end{array}$ & $\begin{array}{r}17 \\
43 \\
120\end{array}$ & $\begin{array}{r}23 \\
101 \\
330\end{array}$ \\
\hline 1.4 & $\begin{array}{l}1 \\
3 \\
5\end{array}$ & $\begin{array}{l}10 \\
10 \\
10\end{array}$ & $\begin{array}{r}10 \\
10 \\
4\end{array}$ & $\begin{array}{l}15 \\
36 \\
63\end{array}$ \\
\hline
\end{tabular}

$n=5$

为什么弱磁场下细胞生长良好而强磁场下细胞 分裂则受到抑制, 且其敏感点是在 G 期 ${ }^{[8]}$. 磁场是通过什么途径来影响细胞的正常生理功能, 除了要从细胞水平的角度来研究磁 场下细胞各结构和成分各种变化之外，我们亦考虑了磁场下细胞内各带电粒子和分子的传递 的变化. 非磁场下,细胞内的带电粒子的运动主要受酶和电场的影响. 例如,在 $G_{2}$ 期,细胞会 有一氧化磷酸化高峰,此时细胞需要为分裂合成大量的 ATP, 在这过程中, 许多游离的 $\mathrm{P}^{3+}$ 以 $\mathrm{PO}_{4}^{4-}$ 的形式被送到各反应中心,这是一定向的输运过程. 由于 $\mathrm{P}^{3+}$ 是带有三价正电的离子而 $\mathrm{PO}_{4}^{3-}$ 常有三价负电的分子,因此在磁场下,其运动轨迹将被局域化在其特有的回旋半径内, 根 据回旋半径公式(用 SI 单位制)我们可以计算出在不同强度的磁场下 $\mathrm{P}^{3+}$ 和 $\mathrm{PO}_{4}^{3-}$ 的回旋半 径。

恒场下带电粒子运动的回旋半径为

$$
r_{i}=\frac{\nu_{i}}{Q_{i}}
$$

其中 $Q_{i}-\frac{Z_{e} B}{m_{i}}, v_{i}$ 取热速度，

$$
v_{i t}-\sqrt{\frac{2 k T_{i}}{m_{i}}}
$$

$k$ 是 Boltzmann 常数.

于是

$$
r_{i}=\frac{\sqrt{A}}{Z} \frac{\sqrt{2 m_{p} k T_{i}}}{e B}
$$

其中 $m_{p}$ 是氢原子质量, $A=\frac{m_{i}}{m_{p}} e$ 为电子电荷, $B$ 为磁场强度.

$$
r_{i}=1.342 \times 10^{-6} \frac{\sqrt{A}}{Z} \frac{T_{i}^{1 / 2}[K]}{B[T]} \mathrm{m},
$$

取 $T_{i}-300 \mathrm{~K}$ (室温), 把长度从 $\mathrm{m}$ 换成 $\mu \mathrm{m}$, 


$$
r_{i}=23.23 \frac{\sqrt{A}}{Z} \frac{1}{B}(\mu \mathrm{m})
$$

对 $\mathrm{P}^{3+}: A-31, Z-3, r, 3+=43.11 \frac{1}{B}(\mu \mathrm{m})$;

对 $\mathrm{PO}_{4}^{3-}: A=95, Z=3, r_{\mathrm{PO}_{4}^{3-}}^{3-}=75.47 \frac{1}{B}(\mu \mathrm{m})$,

因此得表 2 .

表 2 不同强度磁场下 $\mathrm{P}^{\mathrm{s}+}$ 和 $\mathrm{PO}^{3}-$ 的回旋半径

\begin{tabular}{|c|c|c|c|c|}
\hline 半径 $(\mu \mathrm{m})$ 地场强度 $(\mathrm{T})$ & 0.05 & 0.1 & 0.4 & 1.4 \\
\hline $\mathbf{P}^{2+}$ 半径 & 862 & 431 & 108 & 31 \\
\hline POF 半经 & 1509 & 755 & 189 & 54 \\
\hline
\end{tabular}

这一结果与磁场对细胞分裂的效应十分吻合, 在 $0.05 \mathrm{~T}$ 磁场下, $\mathrm{P}^{3+}$ 和 $\mathrm{PO}_{4}^{3-}$ 的回旋半 径远远大于细胞的长度 $400 \mu \mathrm{m}$, 因此 $0.05 \mathrm{~T}$ 磁场不约束 $\mathrm{P}^{\mathrm{s}}$ 和 $\mathrm{PO}_{4}^{3-}$ 的运动, 不影响它们的 自由传递,甚至有可能使 $\mathrm{P}^{3+}$ 和 $\mathrm{PO}_{4}^{3-}$ 更加定向和同步地向反应中心聚集,反而加速了反应. 因而在 0.05T 磁场下能向细胞提供一定的能量。当细胞在 $0.1 \mathrm{~T}$ 恒场下， $\mathrm{P}^{3+}$ 和 $\mathrm{PO}^{3-}$ 的回旋 半径与细胞大小差异不大, 因此实验组和对炤组的细胞数也无明显不同. 当细胞被置于 $0.4 T$ 磁场下时, $\mathrm{P}^{3+}$ 和 $\mathrm{PO}^{3-}$ 回旋半径都小于细胞的尺寸,这一结果说明在细胞内 $\mathrm{P}^{3+}$ 和 $\mathrm{PO}_{4}^{3-}$ 不 能顺利地向反应中心集结. 在 $G_{2}$ 期或多或少要影响氧化磷酸化的过程,使部分细胞的分裂受 到影响. 当磁场开高到 $1.4 \mathrm{~T}$ 时, $\mathrm{P}^{3+}$ 和 $\mathrm{PO}_{4}^{3-}$ 的回旋半径仅为 31 和 $54 \mu \mathrm{m}$, 也就是说它们 的运动、传递被局域化在 31 和 $54 \mu \mathrm{m}$ 范围内, 对于长度约 $400 \mu \mathrm{m}$ 的细胞来说, 它们要顺利的 加细胞的反应变得困难多了. 自然也就影响了细胞的分裂. 以上结果指示我们以不同大小 的细胞来进行验证: 四膜虫（TeTrahymena）长约 $30 \mu \mathrm{m}$, 将其置于 $1.4 \mathrm{~T}$ 磁场下,未见其分裂 与对照组有明显区别. 这说明考虑磁场通过影响细胞内带电粒子的运动传递进而影响细胞分 裂的机制是成立的. 当然细胞分裂是一很复杂的综合过程, 只考虑分子传递不考虑细胞内其 它结构的变化和影响是不妥当的,磁场对细胞所产生效应的各种机制正在逐步深入探讨。

\section{考文執}

[1] Jension, M. W., J. Bacteriol., 33(1937), 15.

[2] Vineent, F. et al., Nature, 196(1962), 529.

[ 3 ] Mulay, I. L., Nature, 190(1961), 1019.

[4] Malinin, G. I. et al., Science, 194(1976), 844.

[5] Rarnothy, M. F., Biological Effects of Mognetic Eield, Vol. 1, Plenum Press, New York, 1964.

[ 6] Mulay, I. L., Nature, 190 (1974), 844.

[7] Tenforde, T. S., Biological Effects and Dosimetry of Static and Elf Electromagnetic Fields, Plenum, 1985.

[8]张小云等,科学通报, 32(1987), 12: 936. 